\title{
When Money Makes Employees Warm and Bright: Thoughts of New Money Promote Warmth and Competence
}

\author{
Aurelia Mok ${ }^{1}$ and David De Gremer ${ }^{2}$ \\ ${ }^{1}$ City University of Hong Kong, Hong Kong, and ${ }^{2}$ University of Cambridge, United Kingdom
}

ABSTRACT Warmth and competence are two important dimensions that facilitate career success (e.g., building relationships, providing novel solutions to problems). We investigated how situational reminders of money affect warmth and competence. Specifically, we propose that reminders of new (vs. used) money increase people's warmth and competence. In five studies of working adults, inducing participants to think about new (vs. used) banknotes promoted creative idea generation (Study 1) (reflecting competence), increased concern for coworkers (Study 2), decreased self-serving behavior (Study 3), and increased helping intentions (Study 5) and behavior (Study 4) (reflecting warmth). Study 4 showed that the effect of priming new money on warmth occurs by activating a norm of social conscientiousness. Our findings suggest that money's appearance can impact problem solving, prorelationship behavior, and perceived norms. We discuss implications for research on money, norm salience, and organizational behavior.

KEYWORDS competence, money, priming, social norms, warmth

\section{INTRODUGTION}

Warmth and competence represent two fundamental dimensions that govern social judgments (Cuddy, Fiske, \& Glick, 2008; Fiske, Cuddy, \& Glick, 2007); people primarily differentiate others on the basis of their perceived warmth and competence (Judd, James-Hawkins, Yzerbyt, \& Kashima, 2005). Warmth is associated with helpfulness, kindness, friendliness, and generosity, whereas competence is associated with capability, ambition, confidence, and intelligence (Fiske, Guddy, Glick, \& Xu, 2002; Judd et al., 2005). In the work context, the dimensions of warmth and competence form the basis for promotion decisions and career success (Casciaro \& Lobo, 2005; Chemers, 1997). For example, leaders are better able to influence followers when they communicate both strength and interpersonal concern (e.g., Livingston \& Pearce, 2009). Employees who demonstrate expertise and approachability are effective in teams and with clients 
(e.g., Barrick, Stewart, Neubert, \& Mount, 1998; Weitz, 1981). Warmth and competence judgments may be positively related (individuals are seen as being high or low in both dimensions) (Judd et al., 2005), but not necessarily. For example, working mothers are typically seen as warm but incompetent, whereas business professionals are typically seen as cold but competent (Cuddy, Fiske, \& Glick, 2004; Tiedens, 2001).

Although work situations often emphasize competence over warmth (Cuddy et al., 2004), warmth is gaining importance. Organizations are increasingly more team oriented, more client centric, and favor transformational leadership - using social skills and warmth to inspire loyalty - over leadership that demands compliance from subordinates (e.g., Bass, 1991). People prefer colleagues who are friendly and helpful (warm), besides ambitious and skillful (competent) (Casciaro \& Lobo, 2005). Moreover, research suggests that a perceived lack of warmth (e.g., selfishness or low sociability), despite high competence, results in judgments of being unsuited to leadership roles (Hyun, 2005; Rudman \& Glick, 2001). Given the importance of both warmth and competence on the work floor, we need to arrive at a better understanding on what specific features relevant to the work setting can promote both dimensions in employees. In the organizational literature, money has been shown to be an effective motivational tool (e.g., Gerhart, Minkoff, \& Olsen, 1995). We build on this idea to propose that money's appearance affects behavior at work. Specifically, we propose that new money elicits higher levels of warmth and competence in employees than used money.

\section{MONEY, WARMTH, AND GOMPETENGE}

Research shows that employees are influenced by the explicit correspondence of money and performance. Financial incentives and compensation can lead to higher performance (Harpaz, 1990; Latham \& Locke, 1986; Lazear, 2000). Financial incentives tend to be linked to displays of competence (e.g., task ability, knowledge, technical skill, productivity) rather than to displays of warmth (e.g., interpersonal skill, socioemotional ability) (e.g., Corell, Benard, \& Paik, 2007; Cuddy et al., 2004). Thus, money should determine employees' levels of competence but not warmth. Indeed, monetary incentives have been found to increase task productivity (reflecting competence) but not helping behavior (reflecting warmth) (Wright, George, Farnsworth, \& McMahan, 1993).

Prior research focused on testing whether people are influenced by the explicit correspondence of money and performance (e.g., Jenkins, Mitra, Gupta, \& Shaw, 1998; Wright, 1989). In the workplace, people's tendencies and actions may also be guided by more subtle cues of money that may not be directly linked to performance. Money can be on people's minds quite often (e.g., budgeting, procurement, forecasting) and thus exert more implicit rather than explicit influences on behavior. To date, there has been very little exploration of how simply thinking about or being 
reminded of money affects employees' tendencies, such as in terms of warmth and competence.

Psychological research, however, suggests that the mere thought of money (even without physical contact) affects people's expressions of warmth and competence. For example, participants who were reminded of money (from exposure to moneyrelated words or images) were less likely to provide or request help and took on more work for themselves compared to participants who were reminded of money-neutral concepts (Mogliner, 2010; Vohs, Mead, \& Goode, 2006). In addition, reminders of money (vs. money-neutral concepts) increased people's tendency to engage in antisocial behavior, such as lying and cheating (Kouchaki, Smith-Crowe, Brief, \& Sousa, 2013). These findings provide some evidence that thoughts of money can lead people to project competence and to disregard warmth. Such effects can occur quite spontaneously, requiring little conscious awareness or intent (e.g., Kouchaki et al., 2013; Vohs, Mead, \& Goode, 2008). Vohs et al. (2008) linked this pattern of responses to money as a key means to self-sustenance. Money is well known to equip oneself with basic resources and promote livelihood, whether materially or socially. Thus, reminders of money could trigger feelings of efficacy and render people more self-reliant and less concerned with others.

In the present paper, we take a broader approach in research of the influence of money on employees. First, drawing on the methodological approach from psychology research (Vohs et al., 2006), we study the impact of reminders of money, not limited to the form of monetary incentives, on people's expressions of warmth and competence. Second, given that money elicits behaviors associated with competence often at the expense of warmth (e.g., regard for others) (e.g., Wright et al., 1993), we examine under what conditions money may increase both warmth and competence. At one time or another, we have all encountered banknotes that are crisp, clean, and new, or used, tattered, and worn (e.g., at retailers, restaurants, the Automated Teller Machine). We propose that new (pristine) money leads to higher displays of both warmth and competence. Moreover, we explore whether this effect potentially holds even without physical contact with money.

\section{Influences of Money's Appearance}

As we discussed previously, reminders of money have been found to engender displays of competence (e.g., Vohs et al., 2006). However, the influence of money's appearance must also be recognized. Very recent evidence suggests that situational cues of new or pristine money make people more likely to exhibit both warmth and competence. For example, exposure to clean (vs. dirty) banknotes led people to exhibit less selfish, unfair behavior in treatment of customers and in economic bargaining games (e.g., how much money to allocate to other study participants) (Yang, Wu, Zhou, Mead, Vohs, \& Baumeister, 2013). These responses appear in line with the dimension of interpersonal warmth (fairness, morality) and prosocial behavior. Furthermore, Di Muro and Noseworthy (2013) found that consumers who 
carried crisp (vs. worn) banknotes felt more confident, proud, and accomplished, which resembles self-viewed competence. Although these papers are important for providing the first evidence of the effects of money's appearance on warmth and competence, they demonstrated the effects in mere money allocation and consumption behavior. Does pristine money (e.g., clean, crisp banknotes) elicit higher levels of warmth and competence only when individuals are making economic or purchase-related decisions? In the current work, we broadened the framework of warmth and competence to include behaviors beyond economic exchanges. We directly tested whether reminders of new/pristine money elicit higher levels of warmth and competence. We studied organizational behavior rather than marketplace or consumer behavior (cf. Di Muro \& Noseworthy, 2013; Yang et al., 2013). In addition, whereas past research focused on money's appearance specifically in terms of whether it is clean (vs. dirty) (Yang et al., 2013) or crisp (vs. worn) (Di Muro \& Noseworthy, 2013), we chose to focus on a more general dimension of money's appearance - new (vs. used). Presumably, 'new' banknotes are clean and crisp, whereas 'used' banknotes are dirty and worn. Our conceptualization could allow for a more complete understanding of the effects of money's appearance, as it takes into account cleanliness and tatteredness.

We go further to examine if physical contact with money is required to generate the effects that we predict. Prior work documented that physical contact with clean, crisp banknotes (vs. tattered banknotes) promoted fairness in monetary exchange (Yang et al., 2013) and self-viewed competence (Di Muro \& Noseworthy, 2013). One could argue that bodily sensations of cleanliness or dirtiness drive the effects. Drawing on a metaphorical relationship between cleanliness and moral purity, psychological research found that physical sensations of cleanliness (vs. dirtiness) led people to be harsher judges of moral misdeeds of others (Zhong, Strejcek, \& Sivanathan, 2010). Clean smells promoted virtuous behavior, as reflected by greater intentions to volunteer and donate to charity (Liljenquist, Zhong, \& Galinsky, 2010). In the organizational literature, physical sensations of dirtiness led leaders to be more lenient towards subordinates who acted unethically (Cramwinckel, De Cremer, \& Van Dijke, 2013). These findings suggest that physical contact with clean or dirty stimuli can transfer the associated properties to the self. It may be the case that touching pristine (vs. tattered) banknotes prompts people to feel pure and renewed, thereby promoting behaviors associated with warmth and competence. We call this the physical sensations account.

However, there is evidence for a nonphysical path from new money to warmth (but not to competence). Yang et al. (2013) found that the act of reading about clean (vs. dirty) money promoted fair allocations of money to others. This suggests that interpersonal warmth does not depend on physical sensations of cleanliness. Nevertheless, physical contact with money was still a part of Yang et al.'s (2013) experimental manipulation; all participants counted ordinary (neither clean nor dirty) banknotes after the reading task. Thus, the extent to which the results were merely driven by mental associations with money is unclear; it may reflect the effects 
of combining physical and nonphysical cues of money. No prior work has tested the possibility that the mere reminder of new money could lead to people expressing greater warmth and competence, that is, without physical exposure to money. We call this the perceptual account. In the current research, we conduct a more systematic analysis of this account for warmth and competence. If thinking about new money in itself predicts warmth and competence, this makes clear that physical sensations of money are not necessary for the effects.

\section{Norm Activation in the Money-Warmth Relation}

Organizational research predominately focuses on how money relates to competence, but not to warmth. There has been a long-standing focus on how money shapes employees' task productivity and output (indicators of competence) (e.g., Bonner \& Sprinkle, 2002; Jenkins et al., 1998), whereas warmth, such as coworker empathy or helpfulness, is rarely assessed. Given that warmth is increasingly important to work situations (Cuddy, Glick, \& Beninger, 2011), organizational researchers need to understand more fully the process connecting money to warmth. We particularly focus on what psychological mechanism may underlie greater warmth as a function of exposure to new money.

In Yang et al.'s (2013) work showing an effect of clean money on fair allocations of money to others (rather than selfishness), the researchers also found that this effect was mediated (explained) by heightened attitudes of fairness (agreement with phrases such as 'fair trade', 'fairness is more important than profit'). While fairness is one form of warmth, the mechanism underlying the effect of money's appearance on warmth has never been tested explicitly.

We propose that the critical mechanism to account for the differences in warmth as a function of money's appearance is norm activation rather than attitudes of fairness alone. We theorize that the pristineness of money can shape beliefs about prevailing social norms. Given that money is a public commodity, used by the self and others, we conceptualize that money that is pristine (vs. dirty, tattered, or torn) would activate a norm of social conscientiousness and, thereby, elicit prosocial, warmth-signaling behaviors rather than self-serving acts. Our hypothesis draws on research suggesting that the appearance of environments can influence whether people engage in prosocial or antisocial acts. For example, vandalism and antisocial behavior is more prevalent in environments with visible damage (e.g., broken windows, graffiti) (Keizer, Lindenberg, \& Steg, 2008). By contrast, people's inclination to litter decreases in clean environments as opposed to dirty, littered environments (Cialdini, Reno, \& Kallgren, 1990). According to the broken windows theory (Wilson \& Kelling, 1982), dirty and disrepaired environments (e.g., littered streets, dirty subway cars) can signal that people are generally self-interested and that selfish or deviant behaviors are tolerated. By contrast, clean public environments can signal that people are less selfish and more considerate of others. The salience of a social conscientiousness norm could increase 
warmth - the tendency to look also to the interests of others and not only to one's own interests. People tend to align their behavior with the salient norm (Berkowitz \& Daniels, 1964; Cialdini et al., 1990; Krauss, Freedman, \& Whitcup, 1978). In sum, we propose that perceived norms of social conscientiousness can account for the link between money's appearance (new/pristine) and warmth.

\section{The Present Research}

Our study makes several unique and important contributions. First, prior studies found that money prompts people to act competently and less warmly (e.g., less helpful) (e.g., Mogliner, 2010; Vohs et al., 2006; Wright et al., 1993). These studies, however, did not take into account the influence of money's appearance. Building on our above theorizing, we believe that the appearance may be an important factor determining whether money also leads to displays of warmth. Therefore, we investigated the relevance of money's appearance to people's warmth and competence. As we discussed earlier, we used a broader, more general operationalization of money's appearance than in past studies (Di Muro \& Noseworthy, 2013; Yang et al., 2013) in order to provide more compelling evidence of its influence. We sought to demonstrate that reminders of new money, relative to used money, can lead people's warmth and competence to increase. We also investigated whether physical sensations related to money are necessary to generate the effects. To validate the perceptual account over the physical sensations account, we tested whether the mere thought of new money, without requiring physical contact with the money, may be sufficient to increase warmth and competence. Nonphysical encounters with money (the sight or thought of money alone) can indeed change people's subsequent thoughts, feelings, and actions (Vohs et al., 2008), yet whether money's appearance (e.g., pristineness) moderates these effects is rarely assessed.

We also examined the psychological mechanism connecting new money to warmth. We tested our norm-activation account that new money would activate a norm of social conscientiousness, thereby leading people to act more prosocial and less self-serving. Thus, our study contributes to research linking norm salience to socially considerate tendencies (e.g., Cialdini et al., 1990).

We examined our hypothesis in work and organizational contexts. Warmth and competence are increasingly important in organizations and to judgments of performance (Cuddy et al., 2011; Rudman \& Glick, 2001). Also, money is so much inherent in everyday social and work life. It occupies people's wallets, minds, and work-related decisions. Our research helps leaders to understand more precisely the impact that money has on employees' feelings and behaviors. We extend the organizational literature by showing when and how money positively impacts people's competence as well as warmth.

To test the hypothesis that new money enhances people's displays of competence and warmth, we report five studies in which we had participants simply think of 
either new or used banknotes and examined the priming influence on multiple ways in which competence and warmth may be communicated in organizations. We tested whether priming new (vs. used) money would promote creativity (Study 1) (reflecting competence), enhance empathic concern for coworkers (Study 2), decrease self-interested behavior (Study 3), increase helping behavior (Study 4), and increase helping intentions (Study 5) (indicators of warmth). If mere thoughts of new money (without touch) can predict the results, this indicates that the effects are not merely due to physical sensations of cleanliness or of money. Such results would validate the perceptual account. Study 4 focused on the mechanism underlying the effect of new money on warmth. We tested whether perceived norms of social conscientiousness can account for this effect. Study 5 examined more precisely the impact of new money on warmth by testing whether the effect is more pronounced than priming (exposure to) newness alone. Collectively, our studies examined whether reminders (activating the concept) of new money have the effect of bolstering individuals' warmth and competence in organizational settings. Finally, because mood has been found to predict positive task and relationship outcomes (e.g., Amabile, Barsade, Mueller, \& Staw, 2005; Carlson, Charlin, \& Miller, 1988), we assessed whether mood could account for the obtained effects in all our studies.

\section{METHOD AND RESULTS}

\section{Study 1}

In Study 1, we sought to provide more direct evidence that money's appearance can influence competence (Di Muro \& Noseworthy, 2013). We assessed the effect of new money on competence using a behavioral measure rather than a self-report measure (Di Muro \& Noseworthy, 2013). We operationalized competence in creative performance. The initial stage of creative output is idea generation (Amabile, 1983). In organizations, coming up with novel ideas and solutions demonstrates competence (e.g., Amabile, 1996). We hypothesized that reminders of new (vs. used) money would facilitate the generation of novel ideas, indicating higher creative performance.

Participants. American working adults $(\mathcal{N}=87 ; 46$ males; mean age $=34.14, S D=$ 11.59; mean years of work experience $=14.17, S D=11.70)$ participated online via Amazon Mechanical Turk. Amazon Mechanical Turk is a valid and commonly used source for survey recruitment (Berinsky, Huber, \& Lenz, 2012; Buhrmester, Kwang, \& Gosling, 2011). Past research on warmth and competence has also recruited from this source (Torelli, Leslie, Stoner, \& Puente, 2014). To be eligible for this study, participants were age 18 or above and currently working/ employed. Hierarchical level in the organization, assessed on a scale of 1 (entry level) to 7 (top level), was near the scale midpoint $(M=3.78, S D=1.69), t(86)=1.21, p=0.23$. The composition of the sample was 74\% White, 6\% Hispanic, 7\% Asian, 10\% Black, and 3\% Other. 
Participant sex, ethnicity (White vs. Non-White), or level in the organization did not affect the results of any studies reported here, so these factors are not discussed further.

Materials and procedure. In an online survey, participants were randomly assigned to one of two experimental prime conditions: new money $(n=43)$ or used money $(n=44)$. In the new money condition, participants were provided with the following instructions:

Imagine you are counting a stack of new banknotes/bills. List five aspects of new bills (e.g., appearance, texture, smell).

In the used money condition, participants were provided with identical instructions except the word 'new' was replaced 'used'.

Next, as a manipulation check, participants in each condition rated their perception of the banknotes along three items: 1 (very worn) to 7 (very crisp), 1 (very dirty) to 7 (very clean), and 1 (touched by very few people) to 7 (touched by a lot of people). We formed an index of money newness by averaging the items after reverse scoring the last item $(\alpha=0.91)$. Afterwards, we assessed mood. Participants rated on a scale of 1 (not at all) to 5 (very much) the extent to which they currently felt happy, relaxed, cheerful, calm, disappointed, tense, depressed, and worried. The items were drawn from Friedman and Förster (2001) and presented in a randomized order. The items for negative mood were reverse scored and averaged with those for positive mood to form a mood score $(\alpha=0.84)$. Higher scores reflect more positive mood.

Then creativity was assessed. We included two measures of idea generation for robustness. The first measure was a spontaneous idea generation task drawn from Mok and Morris (2010, Study 2). Participants were asked to generate examples of several categories, and the novelty of the ideas was assessed. Specifically, participants were asked to name one example of the following categories: animal, fruit, outdoor activity, appliance, furniture, and vehicle. To code the novelty of ideas, we followed the steps outlined by Ward, Patterson, Sifonis, Dodds, and Saunders (2002). Each example that participants generated received a score based on the number of times that example appeared in the sample. For example, for the animal category, 19 participants listed 'cat', so each 'cat' response was given a score of 19. In contrast, four participants listed 'cow', so each 'cow' response received a score of 4. Lower values indicate more novel thinking. We averaged the scores across categories for each participant to form an overall index of novel thinking $(M=27.46, S D=7.10)$. A higher score reflects that participants' ideas were on average more common, whereas a lower score reflects that participants' ideas were on average more unique or novel (see Goncalo \& Staw (2006) for a similar coding procedure).

The second creativity measure was taken from Mok and Morris (2010, Study 1), originally adapted from Rubin, Stoltzfus, and Wall (1991). Participants read: 'Imagine that for a work assignment, you are asked to create new labels for products. Please create a new product label for each of seven product categories'. For each 
category (nuclear element, pain reliever, beverage, flower, font, cocktail, pasta), six examples were provided. To illustrate, for the beverage category, the examples were gatorade, ribena, lemonade, orangina, accelerade, kool-aid. Novel labels were those that did not contain the endings of the examples (i.e., -ade, -na, -aid). We formed a novel labels score by summing the number of labels that did not share word endings with the examples provided $(M=4.13, S D=1.65)$, following Mok and Morris (2010).

At the end of the survey, we included an open-ended study comments box to probe for suspicions. In the current study, and our subsequent studies, no participants guessed the true purpose of the money description task (i.e., to assess carryover effects), suggesting that none were aware of the hypothesis.

\section{Results and Discussion of Study 1}

Preliminary considerations. To check the effectiveness of the manipulation, a one-way analysis of variance (ANOVA) on the money newness index showed a main effect of prime, $F(1,85)=116.75, p<0.001$. Banknotes in the new money condition were rated higher on newness $(M=6.00, S D=1.49)$ than banknotes in the used money condition $(M=2.73, S D=1.33)$. This suggests that the manipulation was successful in activating the concept of new versus used money.

Mood did not differ significantly by prime condition $\left(M_{\text {new }}=3.24, S D=\right.$ $\left.0.47 ; M_{\text {used }}=3.24, S D=0.55\right), F<1$. Mood was not correlated with novel thinking or novel labels $(r(87)=0.07$ and 0.05 , respectively, $p \mathrm{~s}>0.51)$. Thus, mood cannot account for the results below. Novel thinking was not significantly related to novel labels $(r(87)=0.09, p=0.40)$. One possible explanation for this lack of association is because the former (novel thinking) task relies on processing that is more spontaneous, whereas the latter (novel labels) task recruits more deliberate processing, given that specific examples were also presented.

Hypothesis testing. For novel thinking, a one-factor ANOVA (money prime: new vs. used) showed a main effect of prime, $F(1,85)=5.72, p=0.019$. As predicted, participants primed with new money generated examples that were more novel than participants primed with used money; the novel thinking score was lower in the new money condition $(M=25.67, S D=7.29)$ than the used money condition $(M=29.22, S D=6.52), 95 \%$ CI $[-6.49,-0.60], d=0.51$.

Results for new labels showed a similar pattern. The main effect of prime was significant, $F(1,85)=4.26, p=0.042$. Participants who were primed with new money generated more novel labels $(M=4.49, S D=1.72)$ than participants who were primed with used money $(M=3.77, S D=1.51), 95 \%$ CI $[0.03,1.41], d=$ 0.44 .

The results show that reminders of new money facilitate creative performance. Participants who were primed with new (vs. used) money demonstrated more novelty-oriented thinking in the absence or presence of exemplars. The effects 
occurred independently of mood and did not require real money (physical contact with money). The results support the perceptual account that merely thinking about new money can increase competence.

\section{Study 2}

In Study 2, we examined whether reminders of new money increase warmth. We predicted that participants primed with new (vs. used) money would have greater empathy for coworkers. We sought to link money's appearance with nonfinancial prosocial behavior (empathic feelings), thus extending prior work (Yang et al., 2013).

We included another prime condition, money in general, in order to provide a more conservative test of the hypothesis. We expected that participants primed with new money would have greater empathy than participants primed with money in general, because the latter should evoke thoughts of new and used banknotes in combination, thus not strongly activating the concept of new money. We used a different manipulation of money than Study 1 to demonstrate the generalizability of the priming effect.

Participants. American working adults $(\mathcal{N}=86 ; 45$ males; mean age $=36.43, S D=$ 13.03; mean years of work experience $=15.45, S D=11.28$ ) participated online via Amazon Mechanical Turk. We required unique participants via the online survey tool so participants do not overlap in any studies here. The eligibility criteria and payment were identical to Study 1. Hierarchical level in the organization, assessed on the same scale as in Study 1, was below the scale midpoint $(M=3.65, S D=$ $1.61), t(85)=2.00, p<0.05$. The composition of the sample was $84 \%$ White, $3 \%$ Hispanic, 5\% Asian, 7\% Black, and 1\% Other.

Materials and procedure. In an online survey, participants were randomly assigned to one of three prime conditions: new money $(n=31)$, used money $(n=28)$, or money in general $(n=27)$. The instructions for the new [used] money condition were as follows:

Imagine you are withdrawing cash from the ATM machine. The machine dispenses new [used] banknotes/ bills. List five aspects of new [used] bills (e.g., appearance, texture, smell).

For the money in general condition, the instructions were similar except that the wording was changed to 'The machine dispenses banknotes/ bills. List five aspects of banknotes/ bills (e.g., appearance, texture, smell)'. Next participants in each condition rated the manipulation check items that assessed money newness used in Study $1(\alpha=0.89)$, followed by the mood measure used in Study $1(\alpha=0.91)$.

Afterwards, participants completed a measure of empathy. On a scale of 1 (not at all) to 5 (very much), participants rated four feelings towards their coworkers 


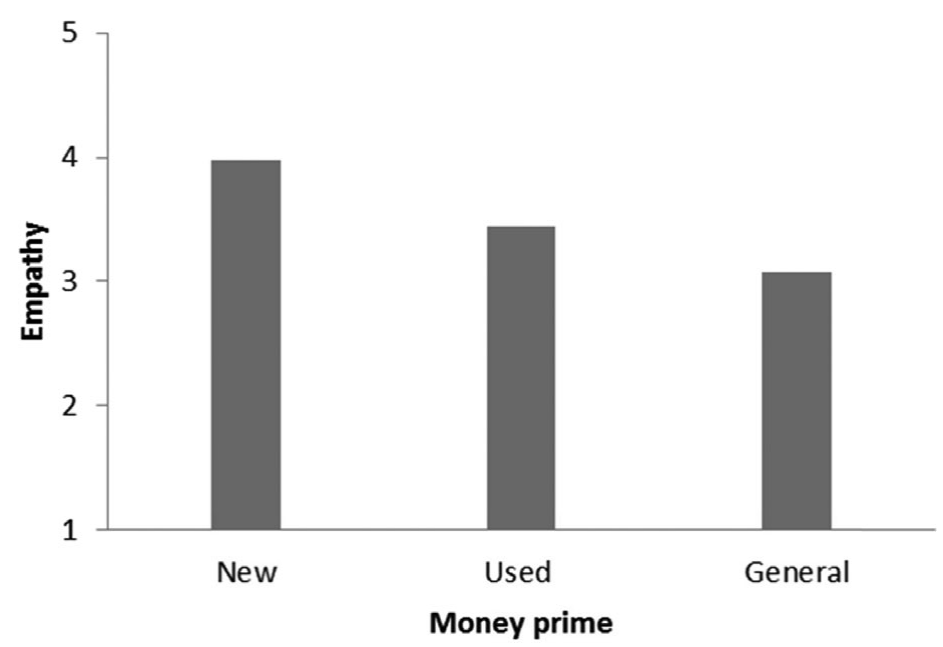

Figure 1. Empathy for coworkers as a function of money priming (Study 2)

(sympathetic, empathetic, compassionate, softhearted; $\alpha=0.87$ ). The empathy items were based on past research (e.g., Wohl \& McGrath, 2007).

\section{Results and Discussion of Study 2}

Preliminary considerations. Ratings of money newness differed across the three prime conditions, $F(2,83)=54.71, p<0.001$. New banknotes were rated higher on newness $(M=6.20, S D=1.28)$ than used banknotes $(M=2.85, S D=1.25)$ and banknotes in general $(M=3.58, S D=1.38)(p \mathrm{~s}<0.001)$. This suggests that the manipulation successfully activated the concept of new money and used money.

Mood differed across the prime conditions, $F(2,83)=3.08, p=0.051$. Specifically, participants in the new money condition reported similar mood $(M$ $=4.19, S D=0.70)$ as participants in the used money condition $(M=3.95, S D=$ $0.89)(p=0.29)$ yet better mood than participants in the general money condition $(M=3.63, S D=0.95)(p=0.015)$. Mood did not differ between the used money and general money conditions $(p=0.17)$. Mood was correlated with empathy $(r(86)$ $=0.30, p=0.005)$. Despite this result, controlling for mood in the analysis below did not change the findings. ${ }^{[1]}$

Hypothesis testing. A one-factor (money prime: new vs. used vs. general) betweensubjects ANOVA showed a main effect of prime on empathy, $F(2,83)=7.44$, $p=0.001$ (see Figure 1). To examine the specific hypothesis of this study, we conducted planned contrast analysis. ${ }^{[2]}$ In line with predictions, participants in the new money condition reported greater empathy for coworkers $(M=3.97$, $S D=0.65)$ than participants in the used money condition $(M=3.44, S D=.84)$, $t(50)=2.63, p=0.011,95 \%$ CI $[0.12,0.92], d=0.62$. In addition, empathy was higher in the new money condition than the general money condition $(M=3.07$, 
$S D=1.13), t(40)=3.60, p=0.001,95 \%$ CI $[0.39,1.39], d=0.90$. Empathy did not differ across the used money and general money conditions $(p=0.18)$.

Study 2 showed that reminders of new money increase warmth, as reflected by greater empathy for coworkers. Priming money in general showed no such effect, indicating that the effect occurs particularly with new money. The effect of priming new money on empathy remained significant even when we controlled for mood. In addition, physical contact with money was not necessary to generate the results, thus validating the perceptual account that merely thinking about new money can foster warmth.

\section{Study 3}

For robustness of the priming effect on warmth, Study 3 examined whether priming new money decreases self-interested behavior. We used a decision-making task in which participants chose how many points to award themselves versus a coworker. We hypothesized that participants primed with new money would allocate points in a less self-serving (more prosocial) manner than participants primed with used money.

Participants. American working adults $(\mathcal{N}=88 ; 54$ males; mean age $=34.41, S D=$ 11.17; mean years of work experience $=14.63, S D=10.66)$ participated online via Amazon Mechanical Turk. The eligibility criteria and payment were identical to Study 1. Hierarchical level in the organization, assessed on the same scale as in Study 1 , was below the scale midpoint $(M=3.66, S D=1.60), t(87)=2.00, p<$ 0.05. The composition of the sample was $72 \%$ White, $2 \%$ Hispanic, $14 \%$ Asian, $10 \%$ Black, and 2\% Other.

Materials and procedure. In an online survey, participants were randomly assigned to one of three prime conditions: new money $(n=28)$, used money $(n=32)$, or money in general $(n=28)$. We used the priming task from Study 1 and included a general money condition as in Study 2. Participants in this condition were told: 'Imagine you are counting a stack of banknotes/ bills. List five aspects of banknotes/ bills in general (e.g., appearance, texture, smell)'. Afterwards, participants in each condition rated the manipulation check items that assessed money newness used in Study $1(\alpha=0.86)$, followed by the mood measure used in Study 1 $(\alpha=0.88)$.

To measure self-interested behavior, participants completed the triple dominance measure of social value orientation (Van Lange, DeBruin, Otten, \& Joireman, 1997). This measure comprises nine games that involve allocating points to the self and another person. We asked participants to complete the task with reference to a coworker of low familiarity - rather than high closeness - in order to provide clearer evidence of the impact of money primes on warmth. Participants were told: 
Imagine you are paired with a coworker whom you do not know well and do not really have a bond with. You will make choices that produce points for yourself and this coworker. The more points you receive, the better for you; the more points your coworker receives, the better for him/her. Example:

Option A: You get 500, Coworker gets 100

Option B: You get 500, Coworker gets 500

Option C: You get 550, Coworker gets 300

Your choice of option (A, B, or $\mathrm{C}$ ) influences the number of points both you and your coworker receive. In the following choice situations, choose the option that you prefer most.

In each game, one option reflected a competitive choice (i.e., maximizing one's gain relative to the coworker's; see option A), another option reflected an individualistic choice (i.e., allocating the highest individual gain to the self; see option C), and another option reflected a prosocial choice (i.e., choosing the highest joint gain or the smallest difference in self-coworker outcomes; see option B). Following recent research (Balliet, Li, \& Joireman, 2011), we formed an overall, continuous measure of self-serving behavior by subtracting points allocated to the self from points allocated to the coworker. Higher (less negative) scores reflect lower selfinterest or greater warmth/prosocial orientation $(\alpha=0.97 ; M=-74.44, S D=$ $117.52){ }^{[3]}$

\section{Results and Discussion of Study 3}

Preliminary considerations. Ratings of money newness differed across the three prime conditions, $F(2,85)=82.16, p<0.001$. Replicating the findings in Study 2, new banknotes were rated significantly higher on newness $(M=6.37, S D=1.17)$ than used banknotes $(M=2.66, S D=1.13)$ and banknotes in general $(M=3.46, S D=$ 1.19) ( $p$ s $<0.001)$. Overall, the manipulation successfully activated the concept of new money and used money.

Mood did not differ significantly across prime conditions $\left(M_{\text {new }}=4.01\right.$, $\left.S D=0.74 ; M_{\text {used }}=3.74, S D=0.86 ; M_{\text {general }}=4.09, S D=0.72\right), F(2,85)=1.66$, $p=0.20$. Mood was not correlated with self-serving behavior $(r(88)=0.09$, $p=0.42)$. Thus, mood cannot account for the results below.

Hypothesis testing. We performed a one-factor (money prime: new vs. used vs. general) between-subjects ANOVA on self-serving behavior. There was a main effect of prime, $F(2,85)=5.34, p=0.006$ (see Figure 2 ). In line with predictions, planned contrasts $^{[4]}$ showed that participants in the new money condition were less selfserving $(M=-19.64, S D=63.39)$ than participants in the used money condition $(M=-87.36, S D=127.58), t(47)=2.65, p=0.011,95 \%$ CI $[10.06,125.37], d$ 


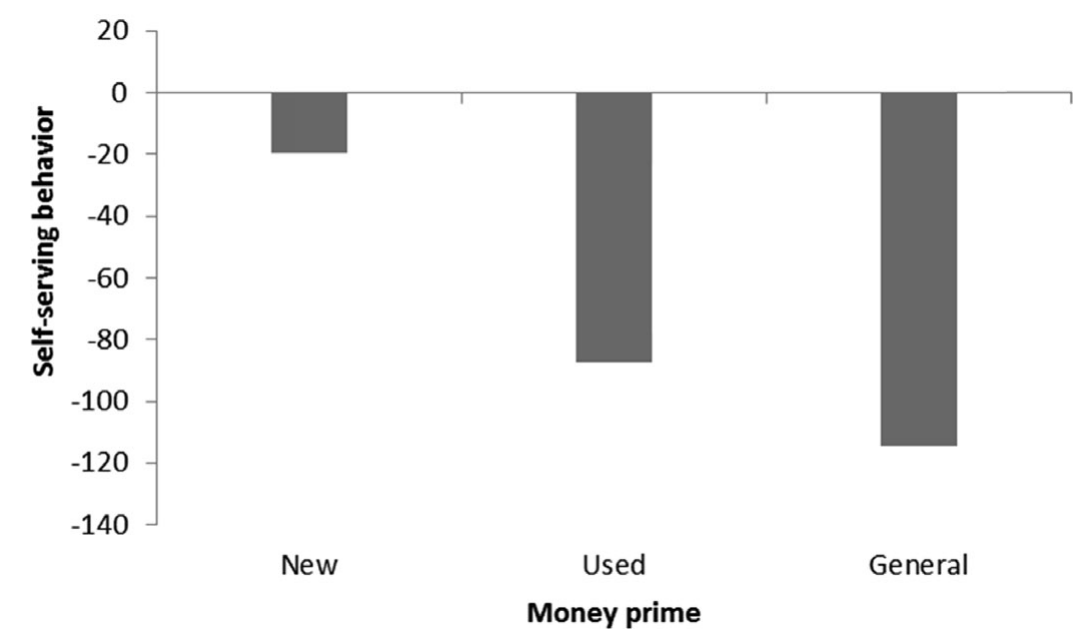

Figure 2. Self-serving behavior as a function of money priming (Study 3)

$=0.67$. Additionally, self-serving behavior was lower in the new money condition than the general money condition $(M=-114.48, S D=129.70), t(39)=3.47, p$ $=0.001,95 \%$ CI $[35.30,154.39], d=0.93$. Self-serving behavior did not differ across the used money and general money conditions $(p=0.42)$.

Study 3 replicated the finding that reminders of new money increase warmth. The reminder of new money not only increases concern for others (Study 2) but also decreases self-serving behavior (Study 3). This effect did not depend on mood and emerged beyond the effect of priming used money or money in general. Priming money in general showed similar effects as priming used money, suggesting that people's general conceptions of money involve used banknotes. Studies 2 and 3 provide convergent evidence for the perceptual account that thinking about new money can promote warmth-signaling behaviors; this effect does not require physical contact with (clean) money.

\section{Study 4}

Although Studies 2 and 3 showed that reminders of new money increase warmth, these studies are not without limitations. For example, we measured self-reports of warmth (Study 2) or warmth in a hypothetical situation (Study 3). It remains unknown whether the results generalize to behavioral displays of warmth and within an actual organization. To address this limitation, in Study 4, we operationalized warmth in helping behavior in an organization. We recruited members of a university (staff, students) and assessed helping behavior toward the researcher, a fellow member of the university. Specifically, we assessed helping behavior at the end of the study in which participants could volunteer (sign up) to help the researcher recruit more participants. We expected that participants primed with new money would be more likely to sign up. These results would provide evidence that reminders of new money can promote interpersonal helping behavior in organizations. 
Furthermore, we tested our proposal regarding the psychological mechanism linking new money to warmth. We argue that new money fosters warmth through activating a norm of social conscientiousness. Past research suggests that the salience of norms can shift in response to the mindset induced in a prior task (e.g., Ybarra \& Stephan, 1999). We tested whether greater perceived norms of social conscientiousness can explain the effect of priming new money on helping behavior.

Finally, we used a different manipulation of money. Research has shown that having banknotes in sight can activate the concept of money (Vohs et al., 2006). To further test the perceptual account that mere reminders of new money (i.e., without physical contact) are sufficient to increase warmth, we had participants look at either new money or used money. In addition, we included a nonmoney control condition (some participants looked at a paper object) to establish whether new money has a unique influence on warmth. Unlike money, paper has no direct association with the behavioral tendencies of others or norms (e.g., Yang et al., 2013). Thus, we expected that priming paper, even that of good condition, would have a limited effect on activating a norm of social conscientiousness and increasing helping behavior.

The main hypothesis in Study 4 is that priming new money will elicit greater helping behavior than priming used money or a paper object. Furthermore, this occurs by increasing perceptions of a social conscientiousness norm.

Participants. Participants were 121 working adults recruited at a university in Hong Kong (26 males; mean age $=21.71, S D=4.52$ ). Participants were recruited through the university's campuswide e-newsletter, circulated to current staff and students, which requested participants for a study on perception. To be eligible, participants were age 18 or above and working part-time or full-time in Hong Kong (mean years of work experience $=2.38, S D=3.56)$. The survey incentive was a chance to win a supermarket gift coupon.

Materials and procedure. In an online survey, participants were randomly assigned to one of three prime conditions: new money $(n=40)$, used money $(n=43)$, or paper $(n=38)$. In the new [used] money condition, participants were presented with a picture of a crisp [worn] banknote. In the paper condition, participants saw a piece of paper from a Post-it note pad (see Figure 3 for the prime stimuli). Participants in each condition were asked to rate the displayed object along three items: 1 (very poor quality) to 7 (very good quality), 1 (very worn) to 7 (very crisp), and 1 (very dirty) to 7 (very clean). We formed a composite score of object newness $(\alpha=0.65)$. Afterwards, participants rated their current mood on one item $(1=$ very bad, $7=$ very good $)$.

Next we assessed norm activation. Participants were presented with 15 everyday situations (e.g., job interview, restaurant, city sidewalk) taken from Gelfand et al. (2011). Participants rated all situations on a scale from 1 (not at all) to 5 (very much) according to three questions adapted from Price and Bouffard (1974) and reported 


\section{(A) New money prime}

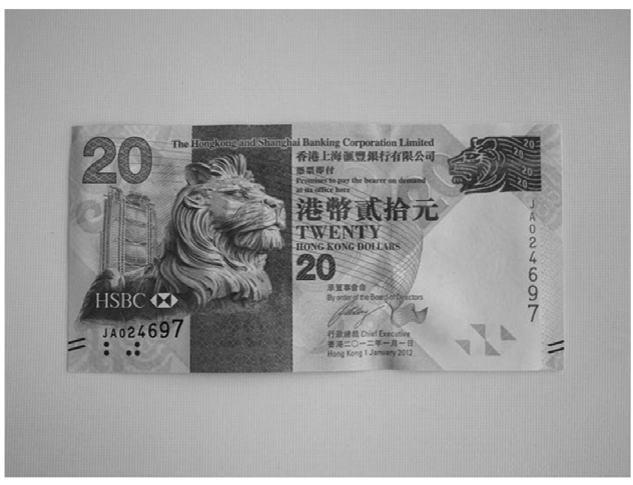

\section{(B) Used money prime}

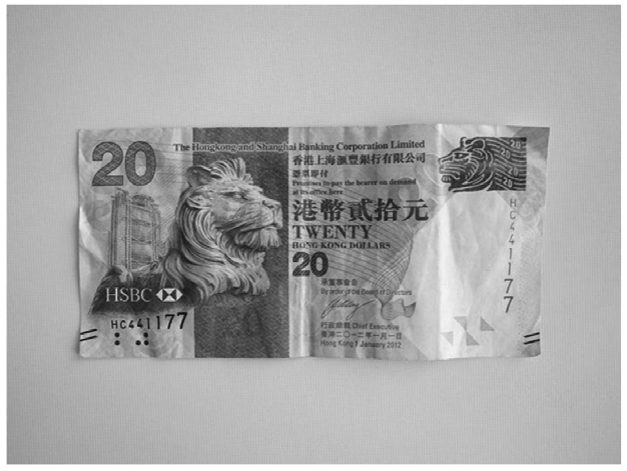

\section{(C) Money-unrelated (paper) prime}

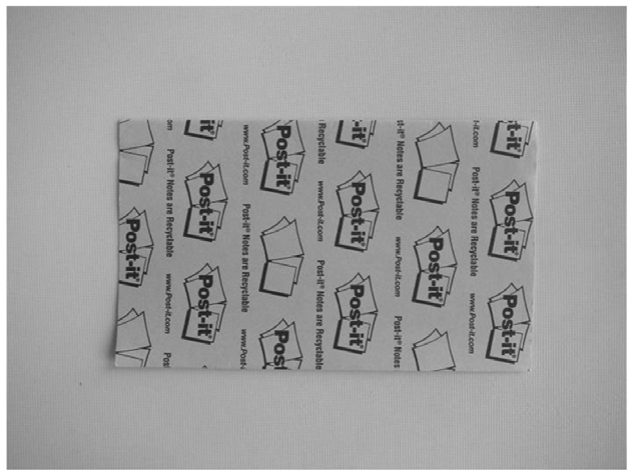

Figure 3. Priming stimuli (Study 4)

in Gelfand et al. (2011) ('To what extent does the setting have clear rules regarding appropriate behavior'?, 'To what extent does the setting call for/demand certain behaviors and not others'?, 'To what extent does the situation require that people monitor their own behavior or 'watch what they do'?). We averaged across the 45 items to form an overall index of perceived norms of social conscientiousness $(\alpha=$ 0.86). Higher scores indicate greater norm salience.

(C) 2016 The International Association for Chinese Management Research 
At the end of the study, after completing a demographic survey, helping behavior was assessed. Participants were presented with a section labeled 'optional'. Here they read 'Will you help to recruit other participants for this study'?, followed by a reminder of the study description (e.g., 'online study on perception'). To help, participants were told to sign up with their email address. Helping behavior was measured in whether participants typed their email address in the space provided. A helping response (providing email) was coded as 1 , and 0 otherwise.

\section{Results and Discussion of Study 4}

Preliminary considerations. An ANOVA on the object newness index showed a main effect of prime, $F(2,118)=10.09, p<0.001$. In line with expectations, the object (banknote) in the new money condition was perceived as newer $(M=4.66, S D=$ 1.04) than the object (banknote) in the used money condition $(M=3.74, S D=$ $0.71)(p<0.001)$. The newness rating for the paper object $(M=4.17, S D=0.74)$ was in between the money conditions: lower than the new banknote $(p=0.011)$ yet higher than the used banknote $(p=0.026)$. Overall, these results suggest that the manipulation induced thoughts of new money, used money, and a relatively new money-unrelated paper object.

Mood did not differ across prime conditions, $F<1$, so mood cannot account for the results below.

Hypothesis testing. We ran a three-factor (new money vs. used money vs. paper) ANOVA on norm salience. The main effect of prime was significant, $F(2,118)=$ $3.43, p=0.036$. As predicted, participants in the new money condition perceived stronger norms of social conscientiousness $(M=3.26, S D=0.30)$ than participants in the used money condition $(M=3.10, S D=0.41), t(118)=2.17, p=0.032,95 \%$ CI $[0.01,0.31], d=0.45$, and the paper condition $(M=3.08, S D=0.27), t(118)=$ $2.36, p=0.020,95 \%$ CI $[0.03,0.33], d=0.63$. The difference between the used money and paper conditions was not significant $(p=0.80)$.

For helping behavior, a dichotomous dependent variable, we ran a logistic regression entering prime (new money vs. used money vs. paper) as the predictor. Prime condition was dummy coded so as to compare the new money condition to the used money condition and also the paper condition. As predicted, participants who were primed with new money were more likely to help (33\%) than participants who were primed with used money $(14 \%)\left(b=1.09\right.$, odds ratio $=0.34$, Wald $X^{2}=$ $3.85, p=0.050)$ or a paper object $(11 \%)\left(b=1.41\right.$, odds ratio $=0.24$, Wald $X^{2}=$ $5.05, p=0.025)$. Helping likelihood did not differ between the used money and paper conditions $(p=0.64)$ (see Figure 4$)$.

Next we conducted a bootstrapping analysis to examine whether perceived norms of social conscientiousness mediated the effect of prime on helping behavior. We followed the steps outlined by Hayes and Preacher (2014), which take into account binomial-dependent measures. As reported earlier, priming new money (vs. used 


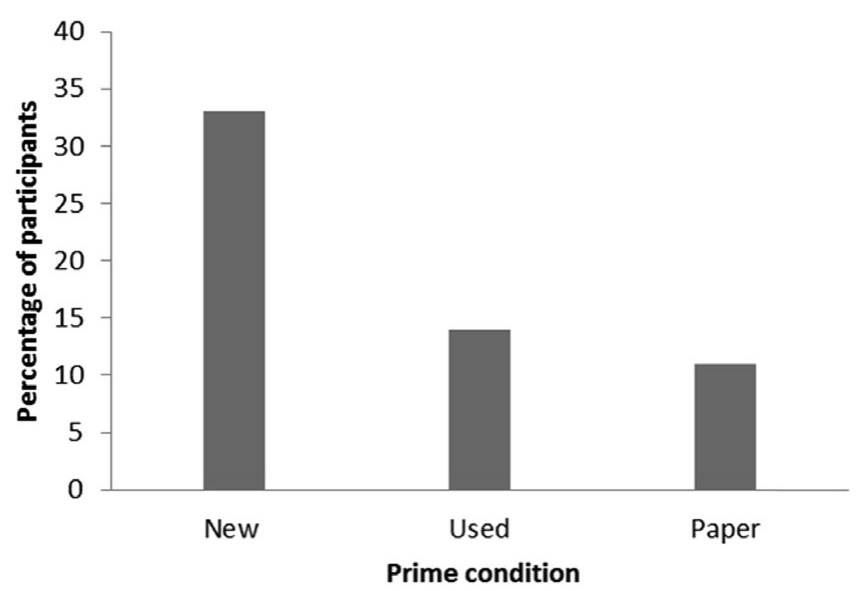

Figure 4. Percentage of participants who chose to help as a function of priming condition (Study 4)

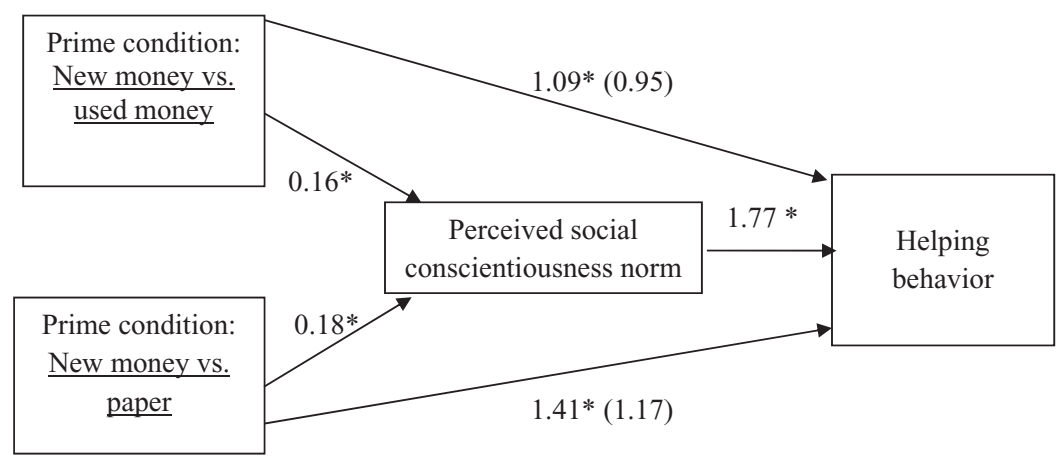

Figure 5. Unstandardized coefficients and indirect effects in mediation analysis of helping behavior (Study 4)

Note: Results using binomial logistic regression analyses. Perceived norms of social conscientiousness mediate the effect of priming new money on helping behavior. Unstandardized regression coefficients are reported. The number in parentheses is the relationship between prime condition and helping behavior while controlling for norm perception. $* p<0.05 . * *<<0.01$.

money) enhanced perceptions of a norm of social conscientiousness $(b=0.16, S E$ $=0.07, p=0.032)$ as did priming new money (vs. paper) $(b=0.18, S E=0.08$, $p=0.02)$. Perceptions of this norm were positively related to helping behavior $\left(b=1.77\right.$, odds ratio $=5.87$, Wald $\left.X^{2}=5.99, p=0.014\right)$. When we added the proposed mediator, perceived norms of social conscientiousness (mean centered) to the model predicting the effect of prime on helping behavior, the effect of norm perception was significant $(b=1.50, S E=0.75, p=0.046)$, whereas the effect of new money (vs. used money) and new money (vs. paper) were reduced to nonsignificance ( $b=0.95, S E=0.57, p=0.096$ and $b=1.17, S E=0.64, p=0.070$, respectively) (see Figure 5). Bootstrap analyses with 5000 iterations yielded 95\% biascorrected confidence intervals that excluded zero [0.002, 0.779 and 0.004, 0.787, respectively]. These results suggest that the activation of a social conscientiousness norm mediated the effect of priming new money on helping behavior. 
Results of Study 4 offer an important extension to Studies 2 and 3, demonstrating that reminders of new money increase warmth at the behavioral level (helping behavior) and within an organization. This effect emerged using a different cognitive manipulation of money - visual cues. We found that visual reminders of new money increased warmth more than visual reminders of used money or paper, thus highlighting a unique influence of new money on warmth. In line with Studies 2 and 3, the results were not dependent on physical contact with money. Mediation analyses supported our conceptualization that reminders of new money activate a norm of social conscientiousness, and this, in turn, leads people to be warm towards others and not selfish.

Based on past findings that reminders of money (vs. money-neutral) concepts lead people to be less helpful (Vohs et al., 2006), one might have expected that, in the current study, priming used money would result in less helping behavior than priming paper. Yet our results revealed no difference between these conditions. These results could reflect the fact that the paper object was perceived as newer than the used banknote and, thus, represents new paper. There is evidence suggesting that new paper and used money produce comparable effects on prosocial behavior. In Yang et al.'s (2013) work, the researchers compared the money priming conditions (clean vs. dirty) against paper priming conditions (clean vs. dirty). While these researchers did not statistically examine the simple effect of priming clean paper versus dirty money, a visual inspection of the means for these conditions across their studies suggests no consistent difference in prosocial behavior. These results could justify our findings that helping behavior did not differ between the paper and used money conditions.

\section{Study 5}

Study 4 suggests that reminders of new money increase people's warmth more than reminders of newness alone, as reflected in greater helping behavior in the new money condition than the (relatively new) paper, money-unrelated condition. Study 5 directly tested whether the effect of new money on warmth is attributable to newness alone (i.e., without money), thus establishing the discriminant validity of the new money effect.

In this study, we used a similar manipulation of money as in Studies 1 through 3 in which participants were asked to think of either new money or used money. We also included two money-unrelated priming conditions as controls. Participants in these conditions were asked to think of either new paper or used paper. Both paper conditions should not serve to prime money but differ in whether the notion of newness or usedness was activated. Our experimental design aligns with Yang et al.'s (2013) work, which included control participants who handled clean or dirty paper for comparisons with participants who handled clean or dirty banknotes. These researchers found that fairness in money allocation was higher in the clean money (vs. clean paper) condition and that fairness was lower in the dirty money (vs. 
dirty paper) condition. Such results suggest that differences in fairness as a function of clean/dirty money cannot be attributed to cleanliness/dirt by itself. Similarly, our results for warmth as a function of priming new (vs. used) money may not be explained by activating newness alone. We hypothesized that warmth would be greater in the new money condition than the used money condition and the new paper condition.

We operationalized warmth as willingness to help colleagues in the workplace. We expected that priming new (vs. used) money would increase willingness to help. Importantly, we tested whether the difference in warmth stems from the specific experience of thinking about the appearance of money (new or used) rather than about newness or usedness in general. If priming new money increases helping intentions more than priming used money or new paper, this analysis would confirm a moderating influence of money's appearance on warmth - that new money indeed predicts greater warmth. We also explored whether helping intentions would be lower among participants primed with used money (vs. used paper), given past evidence suggesting that dirty money promotes more selfish tendencies than dirty paper (Yang et al., 2013).

Participants. Participants were 88 working adults recruited at a university in Hong Kong (20 males; mean age $=23.11, S D=6.86$; mean years of work experience, $M=4.00, S D=5.82$ ). The eligibility criteria were the same as in Study 4 . Participants were invited to complete a brief online survey with a chance to win a supermarket gift coupon.

Materials and procedure. The design of the study was a 2 (money: money vs. paper) $\times$ 2 (newness: new vs. used) between-subjects design. In an online survey, participants were randomly assigned to one of four priming conditions: new money $(n=20)$, used money $(n=21)$, new paper $(n=22)$, or used paper $(n=25)$. We manipulated money (new or used) using the same priming task as in Study 1. In the new [used] paper condition, participants were provided with identical instructions as in the money-priming conditions, except that the wording differed slightly: 'Imagine you are counting a stack of new [used] paper. List five aspects of new [used] paper (e.g., describe its appearance, texture, smell)'. Afterwards, participants rated the one item mood measure used in Study 4.

To assess warmth, participants read, 'Rate the extent to which you would engage in the following behaviors in the coming month'. On a scale of 1 (not at all likely) to 5 (very likely), participants completed four items from the interpersonal helping scale adapted from Moorman and Blakely (1995) and reported in Van Prooijen, De Cremer, Van Beest, Ståhl, Van Dijke, and Van Lange (2008) ('Going out of your way to help coworkers with work-related problems', 'Adjusting your work schedule to accommodate other employees' requests for time off', 'Going out of your way to make newer employees feel welcome in the workgroup', 'Showing genuine concern and courtesy toward coworkers even under the most trying business or personal 


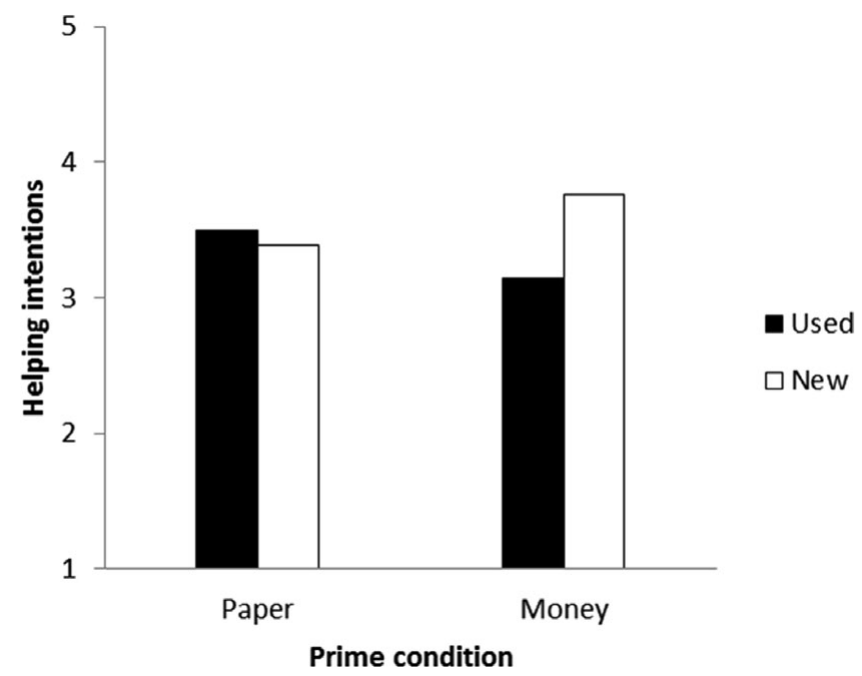

Figure 6. Helping intentions toward coworkers as a function of priming condition (Study 5)

situations'). The items were averaged to form a single index of helping intentions $(\alpha=0.63)$.

\section{Results and Discussion of Study 5}

Preliminary considerations. Mood did not differ as a function of money priming or newness priming or their interaction $\left(F_{\mathrm{S}}<1\right)$. Because mood did not change in response to the priming, mood cannot account for the findings below.

Hypothesis testing. We conducted a 2 (money: money vs. paper) $\times 2$ (newness: new vs. used) ANOVA on helping intentions. Results showed a main effect of newness priming, $F(1,84)=4.34, p=0.040$. The main effect of money priming was not significant $(F<1)$. More importantly, the predicted interaction effect between money priming and newness priming was significant, $F(1,84)=9.11, p=0.003$ (see Figure 6). As expected, the new money group $(M=3.76, S D=0.50)$ reported stronger helping intentions than the used money group $(M=3.14, \mathrm{SD}=0.52)$, $F(1,84)=12.19, p=0.001,95 \%$ CI $[0.27,0.97], d=1.22$. Helping intentions did not differ between the new paper group $(M=3.39, S D=0.53)$ and the used paper group $(M=3.50, S D=0.68), F(1,84)=0.47, p=0.50,95 \%$ CI $[-0.44,0.22]$. Simple effects analysis within level of newness revealed that helping intentions were stronger in the new money group than the new paper group, $F(1,84)=4.60, p=$ $0.035,95 \%$ CI $[0.03,0.73], d=0.72$. Also, helping intentions were weaker in the used money group than the used paper group, $F(1,84)=4.51, p=0.037,95 \% \mathrm{CI}$ $[-0.69,-0.02], d=0.59$.

Study 5 provides further evidence for our hypothesis that new money has a positive effect on warmth. We observed greater warmth (i.e., helping intentions) 
for participants primed with new money than used money. Furthermore, this effect was not merely due to priming newness or usedness. The money priming effect was not equivalent to paper (nonmoney) priming effects. Participants in the new money group exhibited greater warmth than the new paper group; participants in the used money group exhibited lower warmth than the used money group. These results suggest that reminders of new money can indeed facilitate warmth. Furthermore, this effect does not require physical contact with money, as in Studies 2 through 4.

In addition, Study 5 dovetails nicely with Yang et al.'s (2013) research showing that the cleanliness of money has specific consequences for people's prosocial behavior in that cleanliness or dirt alone did not yield equivalent effects. In their studies, clean or dirty paper elicited fairness levels that were in between the clean money and dirty money conditions. Our study complements and extends Yang et al.'s (2013) findings by using a different money manipulation (manipulating the newness of banknotes; activating the notion of money without requiring participants to handle money) and documenting consequences for prosocial behavior (warmth) beyond the realm of money allocation.

\section{DISGUSSION}

Five studies provide support for our hypothesis that money's appearance influences the extent to which people express warmth and competence. Reminders of new (vs. used) money increased people's competence (novel idea generation, Study 1) and warmth (empathy, Study 2; giving behavior, Study 3; helping behavior, Study 4; helping intentions, Study 5). Controlling for mood did not change the results. Despite evidence that positive mood can predict warmth and competence (e.g., Amabile et al., 2005; Carlson et al., 1988), our findings suggest that reminders of new money can increase warmth and competence, independent of mood.

In our experiments, participants were reminded of money at a conceptual level - thinking about new or used money, without coming into physical contact with money. That the idea of new money alone (i.e., without touch) caused people to display warmth and competence casts doubt on an account based on physical sensations. That is, touching clean or new money may confer a sense of renewal (morally, intellectually) and, thus, promote warmth and competence. The current work documents a purely psychological path from new money to warmth and competence. Our findings suggest that money plays a larger and more nuanced role in organizational behavior than previously assumed.

Whereas prior work suggests that money leads people to feel efficacious yet devoid of warmth (see Vohs et al., 2008 for a review), our work indicates that money can have positive consequences for people's warmth. This can depend on money's appearance, such as whether it is used or new. Even though the present findings are in line with recent evidence suggesting that new money increases people's warmth and competence, the evidence presented was not as comprehensive as ours. For example, Di Muro and Noseworthy's (2013) study suggests that crisp (vs. worn) 
banknotes increase people's feelings of competence, whereas we investigate displays of competence. Yang et al.'s (2013) work indicates that clean (vs. dirty) banknotes increase fairness in money allocation, whereas we examine aspects of warmth besides fairness and that transcend the economic realm. Moreover, our findings provide the first evidence of effects in organizational settings (characterized by interdependent social relationships) rather than consumer settings, and without physical exposure to money. Merely activating thoughts of new money can elevate people's warmth and competence. We demonstrate the robustness of this effect using a variety of money priming manipulations and measures directly related to competence and warmth.

The current work documents that a focus on new money is capable of increasing people's warmth and competence beyond a focus on used money or money in general. Further evidence that new money fosters warmth came from our final study (Study 5), which explored whether newness by itself (i.e., without money) can similarly increase warmth. Results showed that helping intentions were more pronounced for participants who had been reminded of new money than for participants who had been reminded of new paper. Reminders of used money yielded lower helping intentions than reminders of used paper. Thus, the effects of priming money and priming newness were interactive; differences in warmth as a function of thinking about new or used money were not merely reducible to thinking about newness or usedness alone. Studies 2 through 5 collectively demonstrate that new money has a positive impact on people's expressions of warmth.

We also document the mechanism underlying the effect of new money on warmth. We posit that money's appearance can signal behavioral norms of the broader community. Money that appears clean, crisp, or new (as opposed to dirty, tattered, or torn) may activate a norm of social conscientiousness, thereby making people act less self-serving and more prosocial. This idea draws on research suggesting a link between the appearance of environments and deviant behavior. Buildings with broken windows attract vandalism (Wilson \& Kelling, 1982). Littered streets attract more litter (Krauss et al., 1978; Schultz, Bator, Large, Bruni, \& Tabanico, 2011). According to the broken windows theory (Wilson \& Kelling, 1982), a damaged, dirty, or unrepaired environment (e.g., broken windows, litter, graffiti) can signal that deviant behaviors are tolerated. Conversely, clean environments (e.g., clean parks, pavement) can signal norms of regard for others rather than selfishness. People align their behaviors with salient norms (Cialdini et al., 1990). Cleaning up the environment could reduce the chances for antisocial acts (Kelling \& Coles, 1998).

Just as a clean environment may convey social mindfulness of others, we propose that pristine money (e.g., clean, crisp banknotes) would foster perceptions of a norm of social conscientiousness. Accordingly, people would become more likely to engage in behaviors that are considerate of others (e.g., more helpful, less self-serving). Results in Study 4 supported this conceptualization, showing that reminders of new (vs. used) money increased perceptions of a social conscientiousness norm. 
Reminders of paper did not show this effect. Furthermore, perceived norms of social conscientiousness were the means with which reminders of new money increased warmth, as reflected by helping behavior. The current findings yield a fuller understanding of the psychological effects of money in documenting that; depending on its appearance (pristineness), money can shift people's behavior in a prosocial direction rather than toward self-interest (e.g., Kouchaki et al., 2013; Vohs et al., 2008). Furthermore, the increase in prosocial behavior is a reflection of aligning one's behavior with perceived norms of social conscientiousness. Our findings contribute to research linking the cleanliness of public settings or property to perceptions of prosocial or unselfish norms (e.g., Cialdini et al., 1990; Wilson \& Kelling, 1982). Whether money, a common public good, appears pristine may influence these norm perceptions.

Our research suggests that warmth and competence can be cultivated in the workplace, whether or not employees have physical contact with cash and banknotes in their work (e.g., stock traders vs. cashiers). Employees are likely to communicate greater warmth and competence by merely cognizing about new money. Further, such money need not stem from organizational incentives, as indicated by the priming manipulations unrelated to work in our studies. This suggests that warmth and competence can result even if employees do not have explicit goals conferred by their organization to display such behaviors. For example, Studies 4 and 5 operationalized warmth in optional, extra-role helping behavior within an organization. Extra-role behaviors refer to discretionary behaviors that are not formally required or explicitly rewarded but help others or the organization (Organ, Podsakoff, \& MacKenzie, 2006). Extra-role behaviors can contribute to long-term organizational effectiveness (Podsakoff \& MacKenzie, 1997). Our results suggest that new money has implications for extra-role workplace behavior.

The present findings have implications for cultures in which rewards in cash are a common practice (e.g., annual lucky draws; red envelopes containing cash in Chinese culture). Prospective and retrospective thoughts of receiving new money are likely to promote interpersonal warmth and competence. Critically, this effect should hold even for cultures that do not place an emphasis on cash or new money. In Chinese culture, new money (e.g., crisp, clean banknotes) is often given together with greetings related to success and well-being (e.g., 事业有成 'may you make achievements in your career', 步步高升 'may your every step take you higher', 龙马精神 'wish you a vigorous spirit', 身体健康 'enjoy good health'), which implies a strong link in memory from new money to competence and warmth. Whereas such practices are not prevalent in Western cultures, Studies 1 through 3, conducted with (mostly White) American participants, showed that reminders of new money promoted competence and warmth. Thus, our findings are unlikely to be culturally specific.

Our research has interesting implications for the financial industry, in which members tend to be highly competitive, self-focused, and ambitious (e.g., Smith, 2012). Although this suggests that dealing with money fuels the pursuit of individual 
competence and success while undermining interpersonal concern and warmth, our findings suggest that both competence and warmth can arise in financial and business settings. This may occur through reminding people of new money.

Future research is needed to advance several aspects of our findings. Our results were based on activating the concept of money, similar to the methodological approach of recent studies (Caruso, Vohs, Baxter, \& Waytz, 2013; Kouchaki et al., 2013; Vohs et al., 2008). How long do the effects of priming new money persist? Do chronic, routine reminders of new money elevate competence that persists across multiple subsequent tasks?

Future studies can provide a systematic analysis of how reminders of new money foster warmth and competence. We provide evidence showing that perceptions of a social conscientiousness norm can mediate the link between new money and warmth. Future work can directly manipulate the norm salience (low or high) to further test our mediation hypothesis (e.g., Bullock, Green, \& Ha, 2010). If our priming effects replicate only when the social conscientiousness norm is not salient, this should lend credibility to our account that perceived norms of social conscientiousness drive the effect of new money on warmth. Our results imply that reminders of new money may heighten self-awareness or public self-consciousness. Future research could explore this possibility.

One question is whether social competence, the ability to manage social interactions and relationships, is a possible mediator of the effect of new money on warmth. For example, Study 2 found that priming new money increased empathy, which can reflect social competence (Marlowe, 1986). Future work could use other measures of social competence (e.g., Cheng, Chiu, Hong, \& Cheung, 2001; Semandar, Robins \& Ferris, 2006) to enable a rigorous test of whether it is a viable mechanism. Another mechanism for the new money-warmth link could be empirically tested. Yang et al. (2013) theorized that people associate clean banknotes with fairness and trustworthiness of the banking system. Could these perceptions, in turn, fuel interpersonal warmth? Future work could examine how priming new money influences competence. To the degree that crisp banknotes make people feel confident (Di Muro \& Noseworthy, 2013), does priming new money increase competence via self-efficacy?

\section{GONGLUSION}

In organizational and work contexts, pay and monetary incentives are typically tied to task productivity rather than consideration of others. Hence, money should be a factor that cues employees to prioritize demonstrating their competence over warmth. Indeed, reminders of money have been previously shown to foster feelings of efficacy, self-reliance, and weaken social bonds. Our research reveals, however, that money may be able to increase both competence and warmth in employees. This depends on money's appearance or pristineness. Reminders of new (vs. used) money lead people to project greater warmth and competence. Real 
money (touching money) is not required for generating these effects. Our findings suggest that focusing on new money can benefit both people's relationships and task performance.

\section{NOTES}

We thank Chi-Yue Chiu for invaluable comments and encouragement.

[1] In all studies, mood as a covariate does not alter the pattern of results.

[2] Levene's test was significant, $F(2,83)=3.87, p=0.025$, implying that variances were unequal across conditions, so degrees of freedom were adjusted from 83 .

[3] Although prior research often derives a categorical measure of prosocial orientation (prosocials vs. proselfs), Balliet et al. (2011) demonstrated that the continuous measure is highly correlated with the categorical measure $r(54)=0.96, p<0.001)$. Consistent with this, in the current study, the continuous measure was highly correlated with the categorical measure $(r(79)=0.96, p<$ $0.001)$.

[4] Levene's test was significant, $F(2,85)=19.51, p<0.001$, implying unequal variances across conditions, so degrees of freedom were adjusted from 85.

\section{REFERENGES}

Amabile, T. M. 1983. The social psychology of creativity: A componential conceptualization.Journal of Personality and Social Psychology, 45(2): 357-376.

Amabile, T. M. 1996. Creativity and innovation in organizations, Vol. 5. Boston: Harvard Business School.

Amabile, T. M., Barsade, S. G., Mueller, J. S., \& Staw, B. M. 2005. Affect and creativity at work. Administrative Science Quarterly, 50(3): 367-403.

Balliet, D., Li, N. P., \& Joireman, J. 2011. Relating trait self-control and forgiveness within prosocials and proselfs: Compensatory versus synergistic models. Journal of Personality and Social Psychology, 101(5): 1090-1105.

Barrick, M. R., Stewart, G. L., Neubert, M. J., \& Mount, M. K. 1998. Relating member ability and personality to work-team processes and team effectiveness. Journal of Applied Psychology, 83(3): 377-391.

Bass, B. M. 1991. From transactional to transformational leadership: Learning to share the vision. Organizational Dynamics, 18(3): 19-31.

Berkowitz, L., \& Daniels, L. R. 1964. Affecting the salience of the social responsibility norm: Effects of past help on the response to dependency relationships. The Journal of Abnormal and Social Psychology, 68(3): 275-281.

Berinsky, A. J., Huber, G. A., \& Lenz, G. S. 2012. Evaluating online labor markets for experimental research: Amazon.com's Mechanical Turk. Political Analysis, 20(3): 351-368.

Bonner, S. E., \& Sprinkle, G. B. 2002. The effects of monetary incentives on effort and task performance: Theories, evidence, and a framework for research. Accounting, Organizations and Society, 27(4): 303-345.

Buhrmester, M., Kwang, T., \& Gosling, S. D. 2011. Amazon's Mechanical Turk: A new source of inexpensive, yet high-quality, data? Perspectives on Psychological Science, 6(1): 3-5.

Bullock, J. G., Green, D. P., \& Ha, S. E. 2010. Yes, but what's the mechanism? (Don't expect an easy answer). Journal of Personality and Social Psychology, 98(4), 550-558.

Carlson, M., Charlin, V., \& Miller, N. 1988. Positive mood and helping behavior: A test of six hypotheses. Journal of Personality and Social Psychology, 55(2): 21 1-229.

Caruso, E. M., Vohs, K. D., Baxter, B., \& Waytz, A. 2013. Mere exposure to money increases endorsement of free-market systems and social inequality. Journal of Experimental Psychology: General, 142(2): 301-306.

Casciaro, T., \& Lobo, M. S. 2005. Competent jerks, lovable fools, and the formation of social networks. Harvard Business Review, 83(6): 92-99.

Chemers, M. M. 1997. An integrative theory of leadership. Mahwah, NJ: Lawrence Erlbaum Associates.

Cheng, C., Chiu, C. Y., Hong, Y. Y., \& Cheung, J. S. 2001. Discriminative facility and its role in the perceived quality of interactional experiences. Journal of Personality, 69(5): 765-785. 
Cialdini, R. B., Reno, R. R., \& Kallgren, C. A. 1990. A focus theory of normative conduct: Recycling the concept of norms to reduce littering in public places.Journal of Personality and Social Psychology, 58(6): 1015-1026.

Correll, S. J., Benard, S., \& Paik, I. 2007. Getting a job: Is there a motherhood penalty? American Journal of Sociology, 112(5): 1297-1339.

Cramwinckel, F. M., De Cremer, D., \& Van Dijke, M. 2013. Dirty hands make dirty leaders?! The effects of touching dirty objects on rewarding unethical subordinates as a function of a leader's self-interest. Journal of Business Ethics, 115(1): 93-100.

Guddy, A. J., Fiske, S. T., \& Glick, P. 2004. When professionals become mothers, warmth doesn't cut the ice. Journal of Social Issues, 60(4): 701-718.

Cuddy, A. J., Fiske, S. T., \& Glick, P. 2008. Warmth and competence as universal dimensions of social perception: The stereotype content model and the BIAS map. Advances in Experimental Social Psychology, 40: 61-149.

Cuddy, A. J., Glick, P., \& Beninger, A. 2011. The dynamics of warmth and competence judgments, and their outcomes in organizations. Research in Organizational Behavior, 31: 73-98.

Di Muro, F., \& Noseworthy, T. J. 2013. Money isn't everything, but it helps if it doesn't look used: How the physical appearance of money influences spending. Journal of Consumer Research, 39(6): 1330-1342.

Fiske, S. T., Cuddy, A. J., \& Glick, P. 2007. Universal dimensions of social cognition: Warmth and competence. Trends in Cognitive Sciences, 11(2): 77-83.

Fiske, S. T., Guddy, A. J., Glick, P., \& Xu, J. 2002. A model of often mixed stereotype content: competence and warmth respectively follow from perceived status and competition.Journal of Personality and Social Psychology, 82(6): 878-902.

Friedman, R. S., \& Förster, J. 2001. The effects of promotion and prevention cues on creativity. Journal of Personality and Social Psychology, 81(6): 1001-1013.

Gelfand, M. J., Raver, J. L., Nishii, L., Leslie, L. M., Lun, J., Lim, B. C., ... \& Yamaguchi, S. 2011. Differences between tight and loose cultures: A 33-nation study. Science, 332(6033): 1100-1104.

Gerhart, B., Minkoff, H. B., \& Olsen, R. N. 1995. Employee compensation: Theory, practice, and evidence. In G. R. Ferris, S. D. Rosen, \& D. T. Barnum(Eds.), Handbook of Human Resource Management, 528-547. Cambridge, MA: Blackwell.

Goncalo, J. A., \& Staw, B. M. 2006. Individualism-collectivism and group creativity. Organizational Behavior and Human Decision Processes, 100(1): 96-109.

Harpaz, I. 1990. The importance of work goals: An international perspective. Journal of International Business Studies, 21(1): 75-93.

Hayes, A. F., \& Preacher, K. J. 2014. Statistical mediation analysis with a multicategorical independent variable. British Journal of Mathematical and Statistical Psychology, 67(3): 451-470.

Hyun, J. 2005. Breaking the bamboo ceiling: Career strategies for Asians. New York: HarperCollins Publisher.

Jenkins Jr., G. D., Mitra, A., Gupta, N., \& Shaw, J. D. 1998. Are financial incentives related to performance? A meta-analytic review of empirical research.Journal of Applied Psychology, 83(5): 777-787.

Judd, C. M., James-Hawkins, L., Yzerbyt, V., \& Kashima, Y. 2005. Fundamental dimensions of social judgment: Understanding the relations between judgments of competence and warmth.Journal of Personality and Social Psychology, 89(6): 899-913.

Keizer, K., Lindenberg, S., \& Steg, L. 2008. The spreading of disorder. Science, 322(5908): 16811685.

Kelling, G. L., \& Coles, G. M. 1998. Fixing broken windozes: Restoring order and reducing crime in our communities. New York, NY: Free Press.

Kouchaki, M., Smith-Crowe, K., Brief, A. P., \& Sousa, C. 2013. Seeing green: Mere exposure to money triggers a business decision frame and unethical outcomes. Organizational Behavior and Human Decision Processes, 121(1): 53-61.

Krauss, R. M, Freedman, J. L, \& Whitcup, M., 1978. Field and laboratory studies of littering. Journal of Experimental Social Psychology, 14(1): 109-122.

Latham, G. P., \& Locke, E. A. 1986. Goal setting: A motivational tool that works. Englewood Cliffs, NJ: Prentice Hall.

Lazear, E. P. 2000. Performance pay and productivity. American Economic Revieze, 90: 1346 1361.

Liljenquist, K., Zhong, C. B., \& Galinsky, A. D. 2010. The smell of virtue clean scents promote reciprocity and charity. Psychological Science, 21(3): 381-383. 
Livingston, R. W., \& Pearce, N. A. 2009. The teddy-bear effect: Does having a baby face benefit Black chief executive officers? Psychological Science, 20(10): 1229-1236.

Marlowe, H. A. 1986. Social intelligence: Evidence for multidimensionality and construct independence. Journal of Educational Psychology, 78(1): 52-58.

Mogilner, C. 2010. The pursuit of happiness: Time, money, and social connection. Psychological Science, 21(9): 1348-1354.

Mok, A., \& Morris, M. W. 2010. Asian-Americans' creative styles in Asian and American situations: Assimilative and contrastive responses as a function of bicultural identity integration. Management and Organization Revieze, 6(3): 371-390.

Moorman, R. H., \& Blakely, G. L. 1995. Individualism-collectivism as an individual difference predictor of organizational citizenship behavior.Journal of Organizational Behavior, 16(2): $127-142$.

Organ, D. W., Podsakoff, P. M., \& MacKenzie, S. B. 2006. Organizational citizenship behavior: Its nature, antecedents, and consequences. London: Sage.

Podsakoff, P. M., \& MacKenzie, S. B. 1997. Impact of organizational citizenship behavior on organizational performance: A review and suggestion for future research. Human Performance, 10(2): 133-151.

Price, R. H., \& Bouffard, D. L. 1974. Behavioral appropriateness and situational constraint as dimensions of social behavior. Journal of Personality and Social Psychology, 30(4): 579 586.

Rubin, D. C., Stoltzfus, E. R., \& Wall, K. L. 1991. The abstraction of form in semantic categories. Memory \& Cognition, 19(1): 1-7.

Rudman, L. A., \& Glick, P. 2001. Prescriptive gender stereotypes and backlash toward agentic women. Journal of Social Issues, 57(4): 743-762.

Schultz, P. W., Bator, R. J., Large, L. B., Bruni, C. M., \& Tabanico, J. J. 2011. Littering in context: Personal and environmental predictors of littering behavior. Environment and Behavior, 45(1): 35-59.

Semadar, A., Robins, G., \& Ferris, G. R. 2006. Comparing the validity of multiple social effectiveness constructs in the prediction of managerial job performance. Journal of Organizational Behavior, 27(4): 443-461.

Smith, G. 2012, March 14. Why I am leaving Goldman Sachs. The New York Times. [Cited 17 July 2015.] Retrieved from URL: www.nytimes.com/2012/03/14/opinion/ why-i-am-leaving-goldman-sachs.html?pagewanted=all

Tiedens, L. Z. 2001. Anger and advancement versus sadness and subjugation: the effect of negative emotion expressions on social status conferral. Journal of Personality and Social Psychology, 80(1): 86-94.

Torelli, C. J., Leslie, L. M., Stoner, J. L., \& Puente, R. 2014. Cultural determinants of status: Implications for workplace evaluations and behaviors. Organizational Behavior and Human Decision Processes, 123(1): 34-48.

Van Lange, P. A., De Bruin, E., Otten, W., \& Joireman, J. A. 1997. Development of prosocial, individualistic, and competitive orientations: Theory and preliminary evidence. Journal of Personality and Social Psychology, 73(4): 733-746.

Van Prooijen, J. W., De Cremer, D., Van Beest, I., Ståhl, T., Van Dijke, M., \& Van Lange, P. A. 2008. The egocentric nature of procedural justice: Social value orientation as moderator of reactions to decision-making procedures. Journal of Experimental Social Psychology, 44(5): 13031315.

Vohs, K. D., Mead, N. L., \& Goode, M. R. 2006. The psychological consequences of money. Science, 314(5802): 1154-1156.

Vohs, K. D., Mead, N. L., \& Goode, M. R. 2008. Merely activating the concept of money changes personal and interpersonal behavior. Current Directions in Psychological Science, 17(3): 208-212.

Ward, T. B., Patterson, M. J., Sifonis, C. M., Dodds, R. A., \& Saunders, K. N. 2002. The role of graded category structure in imaginative thought. Memory \& Cognition, 30(2): 199-216.

Weitz, B. A. 1981. Effectiveness in sales interactions: A contingency framework. Journal of Marketing, 45(1): 85-103.

Wilson, J. Q., \& Kelling, G. L. 1982. Broken windows. Atlantic Monthly, 249(3): 29-38.

Wohl, M. J., \& McGrath, A. L. 2007. The perception of time heals all wounds: Temporal distance affects willingness to forgive following an interpersonal transgression. Personality and Social Psychology Bulletin, 33(7): 1023-1035. 
Wright, P. M. 1989. Test of the mediating role of goals in the incentive-performance relationship. Journal of Applied Psychology, 74(5): 699-705.

Wright, P. M., George, J. M., Farnsworth, S. R., \& McMahan, G. G. 1993. Productivity and extrarole behavior: The effects of goals and incentives on spontaneous helping. Journal of Applied Psychology, 78(3): 374-381.

Yang, Q., Wu, X., Zhou, X., Mead, N. L., Vohs, K. D., \& Baumeister, R. F. 2013. Diverging effects of clean versus dirty money on attitudes, values, and interpersonal behavior. Journal of Personality and Social Psychology, 104(3): 473-489.

Ybarra, O., \& Stephan, W. G. 1999. Attributional orientations and the prediction of behavior: The attribution-prediction bias.Journal of Personality and Social Psychology, 76(5): 718-727.

Zhong, G. B., Strejcek, B., \& Sivanathan, N. 2010. A clean self can render harsh moral judgment. Journal of Experimental Social Psychology, 46(5): 859-862.

Aurelia Mok (aggmok@cityu.edu.hk) received her PhD in Management from Columbia University. She is currently an assistant professor in the Department of Management at the City University of Hong Kong. Her research examines how individuals respond to reminders of money and the implications for judgment, decision-making, and behavior. She is also interested in cross-cultural psychology and consumer behavior.

David De Cremer (d.decremer@jbs.cam.ac.uk) is currently the KPMGfunded chair in management studies at Cambridge Judge Business School, University of Cambridge (UK). In 2014, he received an honorary professorship at the University of Wenzhou, China. Before moving to Cambridge, he was a professor of management at China Europe International Business School (CEIBS; Shanghai) and a visiting professor at London Business School (LBS). He studies business ethics, decision-making, fairness, and trust, with a special interest in China.

Manuscript received: May 30, 2014

Final version accepted: July 18, 2015 (number of revisions - 2)

Accepted by: $\quad$ Senior Editor Chi-Yue Chiu 